\title{
The role of Eco-tourism in sustainable development: case study eco-tourism challenges in Iran
}

\author{
Ismael Rezaeinejad*, and Amol Khaniwadekar \\ Peoples' Friendship University of Russia (RUDN University), Miklukho-Maklaya Street, 6, 117198, \\ Moscow, Russian Federation
}

\begin{abstract}
Sustainable development is a new concept formed after the industrial revolution and the problems created concerning industrialization of cities and technological development of cities and linking different economic, cultural, political, and social development and exceptional attention to ecological considerations. Sustainable development has a comprehensive, integrated and human-oriented approach. It includes valuable concepts in preserving, promoting, and improving health and ecological integrity in the long term and providing human needs. Without destroying the next generation's ability and achieving economic dynamism, a livable environment and social equality are critical dimensions. The importance of conservation of natural resources in the urban environment is as significant as one of the essential areas of development of communities and, at the same time, a criterion for improving the quality of life. The consequences of urban development and the complexity of environmental problems have the inevitable existence of green spaces and their development. Due to the role of urban management in achieving sustainable urban development, this research tries to explain the concept of urban management, its objectives, and its components and provide effective urban management to achieve sustainable development. Eco-tourism is mainly based on resources that the natural environment is available to tourists that use it and appropriate conditions and requires protection of natural resources, which can be realized through evaluation of capability and capacity of the natural environment to attract tourists. The unique geography and diversity of natural phenomena caused Iran to be recognized as the fifth most crucial natural diversity globally, but planning for using these conditions is still not provided. In addition, the country's eco-tourism is faced with social, economic, and environmental problems, and for planning in the field of overcoming this challenge, we first need to recognize these challenges.
\end{abstract}

\section{Introduction}

In the current era, the acceleration of modern urban life and culture led to decreased social interaction between citizens and neglect of the importance of public spaces for these social

${ }^{*}$ Corresponding author: 1032205254@pfur.ru 
interactions. Therefore, the importance of urban green space in life and its sustainability and its physical and social impacts in the urban system is impossible, so the existence of green space in cities and its appropriate distribution is one of the fundamental issues in urban planning. one of the other issues related to the importance of green space use in cities is multifunctional. The natural, aesthetic, social of this land use makes it essential to deal with this issue in the urban area. Population increase and its concentration at the regional level directly affect the quality of the environment [5]. Population growth, poverty, and environmental degradation in developing countries have created a vicious circle. The vicious circle of quality of life has affected people's quality of life and has made the efforts of the third world countries to achieve sustainable development. One way to achieve sustainable development is to have welfare and comfort in the life of society [3]. Today, all governments and authorities of society are providing welfare and peace to the people. The welfare and comfort of life are divided into material and spiritual parts. That spiritual comfort is one of the most critical factors in providing welfare and well-being in crowded spaces of urban green spaces, which has a significant impact on the welfare of citizens. Today, urban planning emphasizes maintaining the relationship between the urban environment and green space and nature [7].

In recent years, eco-tourism has grown significantly in different policy communities and public institutions and sustainable development and created a wide range of challenges between extremist supporters and irrational usage of natural capacity with conservation perspectives sustainable use of these natural resources. However, in most developing countries, little attention has been given to global warming, environmental protection, or commercial activities' carbon effects [8].

Increasing population growth and limited capacity of natural resources include the use of divine gifts for future generations, which is, directly and indirectly, related to nature and is the primary motivation of the visit and the use of natural attractions and indigenous culture without any disruption [2]. The most important incentive to encourage tourists to visit natural attractions today is tourists' curiosity in recognizing and studying rare plant and animal species and natural resources that increase their deeper appreciation of nature, which ultimately stimulates the sense of protection of natural environments [1]. Adventure goals in meeting phenomena and specific natural effects associated with sport, recreation, and hedonic and compelling attractions in health care and physical health, such as hot water springs, are also the other incentives known as Tourist factors. The problems of urbanization caused by migration and population in cities, climate change and ecosystems change due to environmental factors, the development of technology, the rise of income, duplication of living conditions in the city forced people to take refuge in nature to relieve the fatigue. Sustainable tourism will respond to tourists and the next generation's current needs and balance environmental, economic, social, and cultural dimensions. That is, sustainable tourism is looking for socio-economic, social, and cultural dimensions. Meanwhile, Iran has unique opportunities that can be used in order to develop eco-tourism. This study reveals the importance and challenges of eco-tourism in Iran.

\section{Materials and Method}

\subsection{Research method}

The present paper is conducted in an analytical-descriptive method. The gathering method is library study, including books, magazines, papers, and electronic resources. This paper explores challenges in sustainable eco-tourism in Iran to introduce eco-tourism and tourism activities in the sustainable development of eco-tourism and natural resources. 


\subsection{Theoretical bases}

\subsubsection{Sustainable development}

The term sustainable development was used for the first time in 1970 in the Declaration on the Environment and Development. The Global Commission of sustainable development will meet the needs of the present generation without compromising the ability of future generations to meet its needs. In other words, radical changes in exploiting the resources, investments, and development of technology are defined as the potential for existing and future resources to meet the needs of the human being [11].

Sustainable development is a process in which natural, social, physical, economic, financial, trade, energy, agriculture, energy, industry, and all other policies are designed that cause development that can be socially and economically sustainable. In other words, sustainable development means managing and conserving natural resources and directing economic and institutional changes so that the present and future needs are regularly met and sustainable [4].

\subsubsection{Sustainable development theory}

The concept of sustainable development theory has emerged in the form of environmental quality in the early 1980. this theory is presented to support natural resources. Sustainable development meets the needs of the present era without compromising the supply of future needs. Sustainable development is a development that is based on human beings and causes human happiness and growth. So, such development ensures sustainable growth and development in all economic, cultural, and social fields. The primary rationale for sustainable development is to improve the standard level of people's lives and the incredible well-being of those who enjoy the benefits of society while avoiding unnecessary costs. Therefore, the main issue of sustainable development is how to achieve continuous development, regard nature and human beings without injustice, and for all human generations. This new attitude is also necessary for urban planning and urban development policy [6].

\subsubsection{Sustainable Urban Development}

The theoretical foundations of land conservation planning are sustainable urban development pattern, balanced density, land use efficiency; attention to the network is continuous from the green spaces of the district and city [3]. This theory suggests a combination of nature-oriented and sustainable development and a strong-based, technology-based, and robust-based structuralism. The most important definition of sustainable development at the Rio summit is as follows: " the development that meets the current needs of the human without compromising the needs of the future generations, and to be considered in the environment and future generations." Although many definitions of sustainable development have been introduced yet, the axis of all definitions is the next generation and attention to the future. In all definitions, attention to the environment and conservation of the environment is considered too.

The principles of sustainable development can be summarized as follows:

1. Attention to the use of renewable sources, such as solar and wind energy.

2. Using less of non - renewable and polluting energies, such as fossil fuels.

3. Pay attention to future generations

4. Attention to the environment and its pollution reduction and attention to environmental cycles. 
A sustainable city is a city that has the lowest consumption of renewable energies, minimum waste, and minimal impact on the environment and can sustain its current function in the coming decades.

\subsubsection{Sustainable Tourism and Eco-tourism}

Sustainable tourism is ecologically safe, economically applicable, socially acceptable, and economically feasible.

Eco-tourism is a form of tourism involving responsible travel to natural areas, conserving the environment, and improving the well-being of the local people. Its purpose may be to educate the traveler, provide funds for ecological conservation, directly benefit local communities' economic development and political empowerment, or foster respect for different cultures and human rights. Since the 1980s, environmentalists have considered eco-tourism critical, so future generations may experience destinations relatively untouched by the human intervention [7].

Generally, eco-tourism deals with interaction with biotic components of the natural environment. Eco-tourism focuses on socially responsible travel, personal growth, and environmental sustainability [11]. Eco-tourism typically involves travel to destinations where flora, fauna, and cultural heritage are the primary attractions. Eco-tourism is intended to offer tourists an insight into the impact of human beings on the environment and to foster a greater appreciation of our natural habitats.

Responsible eco-tourism programs include those that minimize the negative aspects of conventional tourism on the environment and enhance the cultural integrity of local people. Therefore, besides evaluating environmental and cultural factors, an integral part of ecotourism is promoting recycling, energy efficiency, water conservation, and creating economic opportunities for local communities. For these reasons, eco-tourism often appeals to advocates of environmental and social responsibility [10].

\section{Result and Discussion}

\subsection{Relationship between sustainable eco-tourism development with Environmental Protection and Natural Resources}

Indeed, sustainable eco-tourism development depends on maintaining the environment and optimum use of available facilities. The impact of eco-tourism on the environment is not unique to participate in leisure activities. However, they need facilities and equipment for their time in the region and have their leisure role. Therefore, planners and designers of tourist facilities must develop comprehensive and detailed plans to prevent and decrease the adverse effects of eco-tourism activities in the environment. On the other hand, it reflects the positive and negative impacts on the environment. Without attention and neglect, this matter has severe risks to wildlife and plant species, and other natural objects and may cause ecological changes in the environment [2].

Undoubtedly, attention to national parks and wildlife and many of their functions such as preserving and supporting watersheds and ecosystems, improving environmental conditions in surrounding areas, and preserving the value of natural heritage in most countries, especially the tourist countries, promoted eco-tourism too.

Environmental protection and optimal use of existing natural attractions are costly today, especially for developing countries and the third world. Therefore, these countries should promote eco-tourism in their national park and the areas that have natural attractions. However, such a move will show people's willingness and effort to find calmness, solitude, 
and contact with nature, and the opportunity to familiarize them with their natural heritage and others. Eco-tourism activities in national parks or any other protected area can be a financial mechanism for regulating these areas and the first means to protect them.

These activities are possible if the type and level of tourism management are favorable and proportionate to the carrying capacity of these areas [5]. Another point is that this attitude will arouse public awareness about the importance of protecting and protecting the environment. the experiences gained from the tourist countries by applying scientific and knowledgeable management in this regard indicate that the obtained income in most cases is necessary for the management of national parks and eco-tourism and sometimes more than necessary. It is evident that achieving sustainable tourism development due to the increasing population growth and the need for their people to play their leisure role, the tourist activity is one of the most complex forms, is possible when host countries think of mixed tourism [9].

Respecting the environment and maintaining it is a culture, and culture is aware of its personality as a thinking being and its relationship with others and the natural environment. Therefore, the care of the environment is a necessary part of a cultural policy. It requires the best training methods to take systematic and rational exploitation of natural resources and data. It is also necessary to create a balance between recreational satisfaction and the protective requirements of natural attractions. The search for such equilibrium must determine the concept and philosophy of meeting the natural and environmental attractions and eco-tourism.

\subsection{Analysis of eco-tourism development in Iran}

Due to the diversity of its natural environment and the abundance of geography and diverse geographical attractions such as waterfalls, straits, rivers, mountains and mountains, temperate climate, and thousands of flora and aquatic plants, Iran can receive many domestic and foreign tourists annually. In other words, such as the infrastructure for eco-tourism is to be created for this country, it will undoubtedly create jobs for residents and economic prosperity.

Culture can help accelerate the positive process of eco-tourism developments; what can be done not only on the media level of the public, but at the textbook level, including the benefits of mass travel in the form of tours, the use of expertise, and company information, prevent waste of time, greater security, and even the cost of travel . all of this needs to be benefited from the atmosphere of friendly social interaction with humans, both thinking and taste as well as learning and influencing generations. In Iran, it is as if the cost of traveling with a tour is above a personal journey. Either way, it should be done cheap. However, it can be seen that people spend more money on foreign trips. One of the reasons for the difference is that Iranian people do not pay enough to see the sights and values of their communities and do not know them. As long as Iranian people do not know the value of their country's attractions, their balance of tourism statistics will be negative. The correction of these perspectives requires deep culture and curriculum.

The other challenge is the awareness of host communities about the value of its natural, cultural, and historical attractions. They need to look at these attractions like an asset. Otherwise, they wipe them out with their own hands, trash the trees, pollute the fountains, and destroy rivers, write souvenirs, and land on the old fort wall, all of this means taping into eco-tourism and sustainable development.

Organizing training classes, encouraging and rewarding popular information in the form of defined projects, providing facilities to the people of host communities to provide facilities for drawing and lodging, and including beautiful solutions for the gradual of environmental 
protection, eco-tourism resources, and cultural and historical values of societies and finally sustainable development.

On the other hand, policymaking in the field of introducing natural attractions and going to nature without focusing on responsible tourism standards, getting away from the correct method of presence in nature by using expertise and information of authorized and specialist companies in nature, cause environmental pollution, impact on eco-tourism resources and even tourism industry.

Lack of comprehensive planning in the country and lack of systematic advertising are critical challenges. Eco-tourism in Iran, with all the extent and diversity, has not yet been identified and compiled, and because of these shortcomings, it cannot be promoted. As a result, there is no ad, or if we have, the organization is not targeted and usually leads to the influx of people to these areas. Suppose the people of the region are trained. In that case, they will design and implement new and rational ways of protecting the environment and the natural and cultural attractions of the region and prevent injury to the region.

Generally, the main challenges of eco-tourism in this country are:

\subsubsection{Economic challenges}

Due to the lack of detection of eco-tourism regions and not being infrastructure for that. Among other economic challenges in eco-tourism, the following are:

- Lack of quality of life: a broader definition of human well-being should be offered in a way that goes beyond economic welfare

- The non - compliance of economic, environmental integration: economic decisions should be adopted according to their impacts on the environment

- The lack of guidance and economic plans in the eco-tourism industry

- $\quad$ The deficiencies and failure of infrastructure services such as the roads

\subsubsection{Social challenges}

Among other challenges, could refer to cultural, social, and cultural challenges that the program of modernization and the culture of all sides profoundly impact. Collective travel culture in the form of the tour is one of the indicators of development by taking advantage of the expertise of host companies that have not yet been institutionalized in Iran. Host communities ' awareness of the value of their natural, cultural, and historical attractions is fundamental. Lack of macro planning in the country and lack of systematic advertising are challenges facing eco-tourism in Iran. Eco-tourism routes in Iran have not yet been identified and developed with all their extent and diversity. Due to the lack of sufficient knowledge, it is not even possible to promote it or even do it; advertising is not organized and purposeful and usually leads to the intrusion of public policy into these areas. Another example of the challenging problem of eco-tourism is the following:

- Lack of commitment between generations: At present, decisions have to be made according to the results on the environmental impact of future generations

- Social justice: All people have the right to have the environment in which they grow and flourish

- Lack of involvement: Institutions should be restructured to make all sounds in the decision-making process

- Lack of security in some desert areas in Iran

- The lack of proper management in the eco-tourist regions

- Lack of ease in obtaining visas to enter the country

- lack of Hotels and resort centers in the eco-tourist regions 
- The cultural divide between the host community and the visitor

- Lack of understanding of the actual value of the country's natural resources by the people ( host community )

\subsubsection{Environmental challenges}

Some of the most critical challenges of eco-tourism in Iran can be pointed out as environmental challenges. Tourism has caused irreparable damage to the Iranian environment by tourism so far, including the excessive exploitation of coastal areas and forest areas of north province by tourists, which have already dealt a deadly blow to the environment of Northern provinces.

Among other challenges in this regard are natural protection, protecting resources, and protecting the animal and animal world.

Therefore, eco-tourism in Iran seems to have a little attention that has the weakness points and threats mentioned in table (1).

Table 1. The most significant weaknesses and threats of eco-tourism in Iran.

\begin{tabular}{|c|c|}
\hline Threats & weaknesses. \\
\hline $\begin{array}{l}\text { showing the negative image from Iran In } \\
\text { international media }\end{array}$ & Lack of comprehensive strategic programs \\
\hline Tension, unrest, insecurity in the Middle East & $\begin{array}{l}\text { unsuitable transportation system to visit specific } \\
\text { areas }\end{array}$ \\
\hline $\begin{array}{l}\text { competition among world countries to attract } \\
\text { tourists }\end{array}$ & $\begin{array}{l}\text { weakness and lack of hotels and suitable } \\
\text { residences for tourists in eco-tourism area }\end{array}$ \\
\hline $\begin{array}{l}\text { The global economic downturn, which has led } \\
\text { to a decline in large numbers of tourists }\end{array}$ & $\begin{array}{l}\text { Lack of skill and human resources in eco-tourism } \\
\text { major }\end{array}$ \\
\hline $\begin{array}{l}\text { environmental degradation, drought, and } \\
\text { natural disasters }\end{array}$ & $\begin{array}{l}\text { weakness in marketing and introduction of } \\
\text { Iranian ecosystems }\end{array}$ \\
\hline $\begin{array}{l}\text { Non - promotion and exclusion of Iran except } \\
\text { some attractive areas by Westerners }\end{array}$ & weakness health care in some destination areas \\
\hline & $\begin{array}{l}\text { Inadequate or non - access to technologies such } \\
\text { as the Internet in some destination areas }\end{array}$ \\
\hline & $\begin{array}{l}\text { lack of attention to eco-tourism attractions and } \\
\text { lack of responsibility for the environment }\end{array}$ \\
\hline & $\begin{array}{l}\text { Weakness and lack of social security, especially } \\
\text { in some remote areas }\end{array}$ \\
\hline & $\begin{array}{l}\text { high inflation rate and economic problems in the } \\
\text { country }\end{array}$ \\
\hline & Cultural problems \\
\hline
\end{tabular}

\subsubsection{Opportunities of Iran eco-tourism}

As a four-season country with pristine and beautiful nature in different parts, Iran has a lot to offer nature lovers and eco-tourists. Another example of the opportunity of eco-tourism in Iran is the following:

- Iran will be on the path of the Silk Road and the link between the world of the West and East Africa as one of the most eco-tourist countries in the world

- Inland waters are recognized as important bird areas with more than 50 inland lakes and 22 internationally important wetlands

- Coastal areas: Caspian Sea (630 km) and the Persian Gulf and Oman Sea (1880 km) and a multitude of islands 
- 80 registered protected areas under the jurisdiction of the Department of Environment

- Many caves, springs, waterfalls, rivers, and geological structures

- the hottest deserts in the world (Lut Desert)

- unique animal and plant species

- the first phase of development of the National Nature-based Tourism Strategy, 2000 naturally attractive sites were identified

\section{Conclusions}

Eco-tourism can have different and significant effects in the region. These effects can be social, cultural, economic, and environmental. Planners and policymakers also use the ecotourism industry as the central pillar of sustainable development. According to the extent of sustainable development of the term, this term is described in different ways. The principle of transformation of relations between the system is social, economic, and natural processes. Considering the importance of the eco-tourism industry and cultural, social, and political factors, natural environment factors play an important role in tourism development and attract tourists. Tourists use a geographical space. This space has a physical and natural structure, including environmental factors, geology, topography, flora, fauna, and some of the factors caused by human beings' activity.

The arrival of tourists to each region has led to employment at the macro level that provides the context for economic, social, and cultural development. Today, the eco-tourism industry has found much development globally. Many countries have improved their status considerably and reduce many of their problems such as unemployment, low-income level, and shortage of foreign exchange income by a city with many eco-tourism potentials.

The results show that Iran can be one of the main axes of eco-tourism. Considering the current situation and identifying the strengths and opportunities of tourism development in the region and on the other hand, the lack of suitable communication channels between cities and, lack of facilities for residential, service and welfare facilities for passengers, weakness of advertising and lack of people willing to invest are main obstacles of eco-tourism development. The development and reconstruction of roads between the provinces, rebuilding roads leading to attractions, creating service facilities, utilities and residential areas for tourist entry, and using well-trained people as tour guides can be grounds for ecotourism development.

Due to the variety of attractions and natural landscapes, Iran is one of the eco-tourism poles. Eco-tourism in terms of economic causes prosperity and construction of rural areas. Planning in eco-tourism is considered the most crucial part of eco-tourism and undoubtedly is one way to achieve sustainable development and eco-tourism.

Eco-tourism can reduce threats through monitoring, local practices, educated people, environmental education, and protected areas. Eco-tourism needs comprehensive planning and management as well as understanding the potential.

As one of the essential tools among all tourism industry sectors, eco-tourism is growing and challenges economic, social, and environmental issues that can be used with proper planning to achieve its primary goal, sustainable development.

\section{References}

1. M. Altinay, K. Hussain, International Journal of Contemporary Hospitality Management (2005) 
2. S. Blangy, H. Mehta, Journal for Nature Conservation, 14(3-4), 233 (2006)

3. D. B. Carson, A.J. Taylor, The Rangeland Journal, 30(1), 77 (2008)

4. J. Davenport, J.L.Davenport, Estuarine, coastal and shelf science, 67(1-2), 280 (2006)

5. D. Harrison, S. Schipani, Lao Tourism and Poverty Alleviation: Community-Based Tourism and the Private Sector. In Pro-poor Tourism: Who Benefits?, 84 (2007)

6. I.G. Malkina-Pykh, Integrated assessment models and response function models: pros and cons for sustainable development indices design. Ecological indicators, 2(1-2), 93 (2002)

7. G.P. Nyaupane, B. Thapa, Journal of Ecotourism, 3(1), 20-45 (2004)

8. I. Rezaeinejad, A. Khaniwadekar, K.S. Rana, SHS Web of Conferences, 114, 01028 (2021)

9. P. Tremblay, Desert tourism scoping study. Desert Knowledge CRC (2006)

10. D.B. Weaver, L.J. Lawton, Tourism management, 28(5), 1168 (2007)

11. M. Whitehead, Urban Studies, 40(7), 1183 (2003) 